As this stain evidently has a large sale, as it is extensively advertised in the magazines and daily papers, cases of dermatitis from its use must be more frequent than the cases reported show. One fact that is liable to mislead the physician is that on account of the sealp being less sensitive to irritants than the skin of the face the scalp is not involved and the connection between an eruption on the face and the application of a dye to the hair is overlooked. The use of hair dyes and face lotions is becoming so common that we must consider them as possible causative factors in any eruption about the face, neck and scalp that we can not class as one of the recognized diseases.

632 Fulton Building.

\section{AN EPIDEMIC OF EMPYEMA}

\section{E. H. MUSSON, M.D.} NORBORNE, MO.

The following experience seems sufficiently remarkable to be worth reporting. The cases mentioned all occurred in my practice during the six months from Dec. 1,1908 , to June 1,1909 , in a rural community having a radius of less than four miles, with the center about seven miles northwest of Norborne, Mo.

I attended in this community six cases of frank lobar pneumonia and eight cases which I diagnosed pleuropneumonia. These latter failed to show clear physical signs of consolidation, the clinical picture being that of a severe pleuritis. All but one, an infant, however, raised a small amount of slightly "rusty" sputum. One of the pneumonia patients and six of the pleuropneumonia patients developed empyema as a sequel. Another pleuropneumonia patient had a large serous effusion, making eight cases of effusion out of the fourteen, seven being purulent and one non-purulent.

The treatment of most of the cases preceding effusion was simple, consisting of good nursing, elimination, very hot applications to the chest for pain, with morphin given in a few instances, and tepid bathing for combating a dangerously high temperature.

The empyema patients ranged from 14 months to 72 years of age. Five were males and two females. In four cases the pus was in the right pieural cavity and in three in the left. I operated twice by incision in an intercostal space and five times by resection of a rib, and all recovered. The gross appearance of the pus was that of a pneumococcus infection. In the case of nonpurulent effusion the patient recovered satisfactorily after the withdrawal of nearly a half-gallon of fluid from the pleural cavity.

\section{THE ASSOCIATION OF ENTEROCOLITIS WITH PNELMONIA}

\section{MARK LIEBERT, M.D. BROOKLYN}

The prevailing epidemic of enterocolitis and pneumo. nia running typical courses side by side will, no doubt, arouse the interest of many practitioners. The field for bacteriologic study should yield much useful information. The two diseases apparently aggravate each other, but the course of either is not otherwise modified. They appear either to arise simultaneously or closely to follow each other. The diarrhea follows the operation of the usual causes, most often occurring in bottle-fed infants or children fed on malted milk, though I have seen a case in an exclusively breast-fed infant.

The simultaneous involvement of the respiratory and gastrointestinal tracts would suggest the presence of a common predisposing cause. In a few cases there was a history of a preceding prolonged bronchitis. The stools are small in amount and occur at great frequency. At tust they are greenish, mucoid and very fetid; later they become serous in character. They may be vellowish, showing particles of curdled undigested milk. In one of my cases the stools were blood-streaked. If diarrhea exists before consolidation has taken place in the lungs, there is usually a temperature between $101 \mathrm{~F}$. and $102 \mathrm{~F}$. With consolidation the temperature may be very high, reaching 105.5 F. Prostration is marked. In one of my cases cough was entirely absent, while the lungs gave typical physical signs. These cases usually occur in the second year, although I had one case in a boy of six.

Treatment should be directed chiefly to the diarrhea. In this I follow the teachings of Dr. Joseph E. Winters, of New York. Castor oil at the outset, starvation for from 24 to 36 hours, with plenty of cold water during this period. I have seen fever go down precipitately under this treatment alone. Even drugs are to be excluded. At the end of from 24 to 36 hours feeding is begun according to age. For children less than $\mathbf{1 0}$ months old, cow's milk is modified so as to minimize proteids; above 10 months cereals are given and milk avoided. I do not think that the exclusion of milk tends to aggravate the course of the pneumonia. The fever is treated by tepid sponging and the ice-bag to the head. High rectal enemas, as shown by Dr. Winters, may increase the cyanosis and tend to produce collapse.

This is writton in the hope that it may interest others whose experience has been extensive in this class of cases. It is a live, timely topic and much may be said that will prove beneficial to all in the treatment of two dangerous affections.

57 Christopher Avenue.

\section{PIN EXTRACTED FROM TRANSVERSE COLON} FRED V. WATSON, M.D. ANTIGO, WIS.

The cases reported in The Journal, one (April 10, 1909) of a darning needle, extracted from epigastrinm of an infant, the other (June 5, 1909) of a scarf pin swallowed by an infant and found protruding from the anus, have prompted me to report a case that occurred in my practice last week.

History.-A young woman, aged 18, with an acute attack of appendicitis second day complained of a sharp sticking pain over the line dividing the right hypochondriac region from the epigastric region. As there was extreme tenderness over $\mathrm{Mr}$ Burney's point with tympanites, colicky pain and vomiting, pulse 120 , temperature $102 \mathrm{~F}$., nothing was thought of this pain, but a diagnosis of acute catarrhal appendicitis was made and immediate operation advised.

operation.-Under ether anesthesia I made my incision directly over McBurney's point, and on searching for the appendix I picked up a part of the transverse colon that contained a pin. This was extracted and the wound closed with a puckering string of Pagenstecher's linen. The appendix was then loeated and found to be in an acute catarrhal condition, curled on itself, with adhesions from a former attack. It was removed in the usual manner and the patient made a good re. covery. The patient has no knowledge of swallowing the pin. 